\title{
The Evaluation of Deflected Mode of Wall Hollow Zone of Standpipe
}

\author{
Alpysbai Imankulovich Ainabekov ${ }^{1}$, Ulanbator Seitkazievich Suleimenov ${ }^{1}$, Medetbek Abildaevich Kambarov ${ }^{1}$, \\ Chfsen Asanbekovich Abshenov ${ }^{1} \&$ Svetlana Nikolaevna Buganova $^{2}$ \\ ${ }^{1}$ M. Auezov South-Kazakhstan State University, Republic of Kazakhstan \\ ${ }^{2}$ Kazakh leading Academy of architecture and civil engineering, Republic of Kazakhstan \\ Correspondence: Alpysbai Imankulovich Ainabekov, M. Auezov South-Kazakhstan State University, Republic of \\ Kazakhstan.
}

Received: December 6, 2014

Accepted: January 20, 2015

Online Published: May 30, 2015

doi:10.5539/mas.v9n6p184

URL: http://dx.doi.org/10.5539/mas.v9n6p184

\begin{abstract}
The result of experimental research of the deflected mode of the wall hollow zone of standpipe model is considered in this article. Significant concentration of stresses in the zone of wall hollows are revealed, as well as the effect of " latching" of the wall model in consequence of redistribution of stresses in the zone of the defect., as well as the dependences of the stress concentration factor on the depth and radius of the hollow is established. The results, which are allowed to prove the necessity of the analyses and design of tank structures of stress concentration in the area of hollows has found. Expressions are obtained by the analyses of stress concentration factors based on the geometric dimensions of hollows in the wall of the tank.
\end{abstract}

Keywords: vertical standpipe, defects in the form of hollows, deflected mode, stress concentration

\section{Introduction}

The vertical standpipe assigned to critical constructions, destruction of which could lead to environmental disasters, considerable material inputs and loss of life. In this regard, their construction and operation should be based on well-founded scientific, technical capabilities, essentially new design and economically defensible decisions. This leads to the need to intensify of research on the development of scientific bases for assessing the strength and stability of the vertical standpipe with the actual operating condition.

Despite the constant improvement of the technology of manufacturing and installation of standpipes, full analysis of operating loads and influences in their designs meet geometrical malconformation that have a essential influence on the deflected mode of the tank body and lead to significant local stress concentrations (1, 2).

Many years of operating experience of vertical standpipes testifies that the most probable sites of origin and development of fracture stress concentrators are: shape defect, joint weld, frames and openings, mechanical failure, geometrical irregularity $(3,4)$. One of the most dangerous and unpredictable zones from the standpoint of stress concentration, for the vertical standpipe zones are hollows, which are currently insufficiently studied (5, $6)$.

It is known that the major causes of hollows in the wall of the standpipe is differential settlement base, deformation and displacement of the transverse and longitudinal shrinkage of vertical and horizontal sections, angular rotation of the cross sections in the plane of the welded elements associated with the sequence of the welded joint.

The results of in-situ investigations of tank structures of a number of objects in South Kazakhstan region (7), given in accordance with Figure 1, shows that the hollows on the walls of vertical standpipes have different geometric shape, depending on the causes of the local deformations of the wall. 


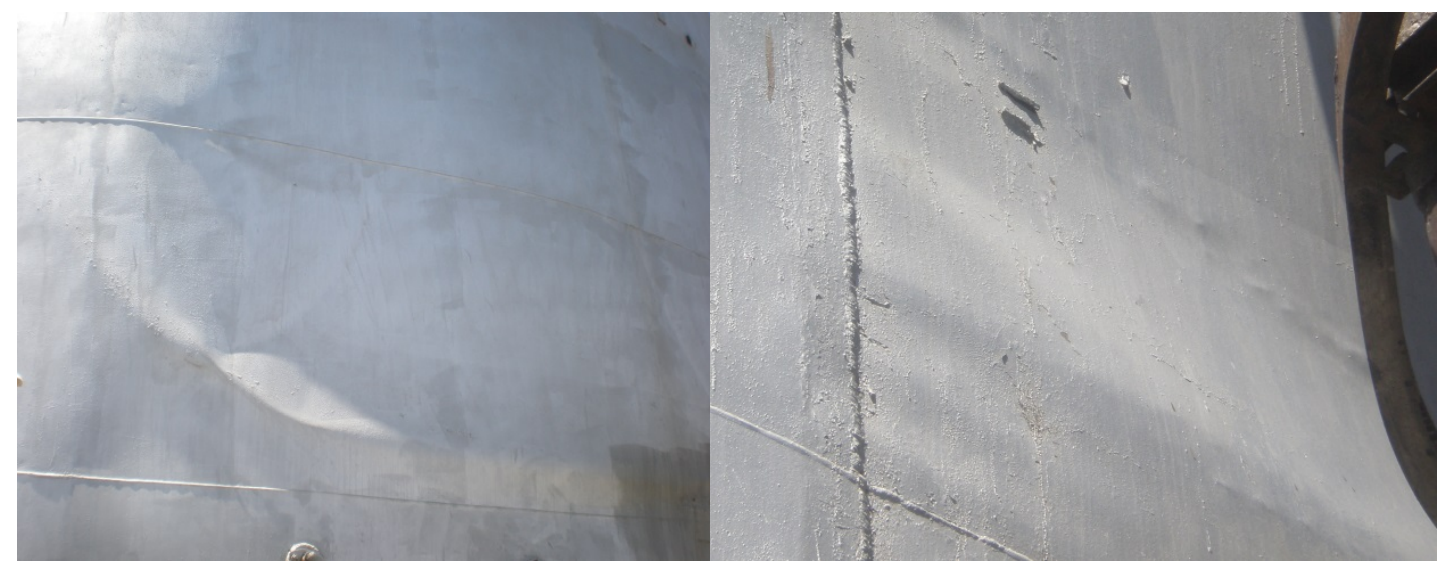

a)

b)

Figure 1. The form of the hollows on the wall of the standpipes in the zone of erection joint

a) the volume of $3000 \mathrm{~m} 3$ in the tank farm of LRP «RTS Oil» s. Ak-su, b) volume $2000 \mathrm{~m} 3$ in the tank farm of LRP "TurkestanOilProduct" Turkestan.

For the hollows, formed as a result of an external mechanical impact during transportation and installation of the tank walls, lozenge-shaped is specific. Such hollows are elongated for perpendicular to the forming of the cylindrical shell, and unlike welding deformation and displacement have small radii and specific edges in the lines of the wall bend.

The analysis of the nature of hollows tanks for white products in oil storage of limited responsibility partnership «Shymkent Octan", shows that, in practice, the possibility of local malconformation in the form of a wavy rough wall surface. The theoretical results are carried out in work (7), suggests that the cause of these defects can be a loss of stability of the wall is accompanied by the formation of a series of elongated hollows, placed angularly to the generatrix of the shell, the boundaries of which can be represented and put in the form of ellipse.

At the same time for today there is no comprehensive and systematic assessment of the concentration of stresses in the hollows, and the existing regulations on the construction and operation of reservoirs for oil and petroleum products is not based upon the characteristics of the deflected mode in the zone of hollows at the strength analysis and durability of tanks, the methods and methods of these calculations have not been developed.

There is little data on the concentration of stresses in the tank wall caused by local malconformation as hollows in the current scientific literature. There is a need to establish the concentration of stress from the geometric dimensions and shape of hollows, its location and the characteristics of the wall material.

The existing regulations for the design, manufacture, installation and operation of vertical standpipes do not contain science-based methods for calculating their strength and durability, taking into account the stress concentration in the zone of hollows, do not regulate the tolerances on the geometrical dimensions of local defects on the wall in the form of hollows $(8,9,10,11,12)$.

In this regard, the results of the study features of deflected mode of hollows zone in the wall of the standpipe is considered in this article.

\section{The Methods of Research}

It is known that the validity of the experimental data and the adequacy of its real phenomena depend on the correct choice of model scale. In this regard, given the characteristics of the thin-walled structures, the technical feasibility of manufacturing the model, the possibility of application of the load and measurement of experimental data, the simulation scale 1:10 accepted to full-scale structural model of vertical cylindrical tank by volume of $5000 \mathrm{~m} 3$.

The thinness of the tank shell and processing limits on the scale of the main structure and the wall does not achieve complete geometric similarity between the model and in-situ object. In connection with this geometric similarity of structure was replaced by an affine correspondence model and design. The modeling of the geometric dimensions and operating load produced by the scaling transformation equations of the momentless theory of shells, based on the two-scale simulations using the method of dimensional analysis of physical 
quantities, which were the result of the similarity criteria and the full-scale model of the tank, as well as the similarity coefficients for forces, stresses, displacements and surface load

The overall dimensions are 1200x1000x160mm. The wall model is made of sheet steel C 255 of $1 \mathrm{~mm}$ thick. Wall model is rolled under radius $2280 \mathrm{~mm}$. General view of the model fragment wall of the tank with hollows is shown in Figure 2.
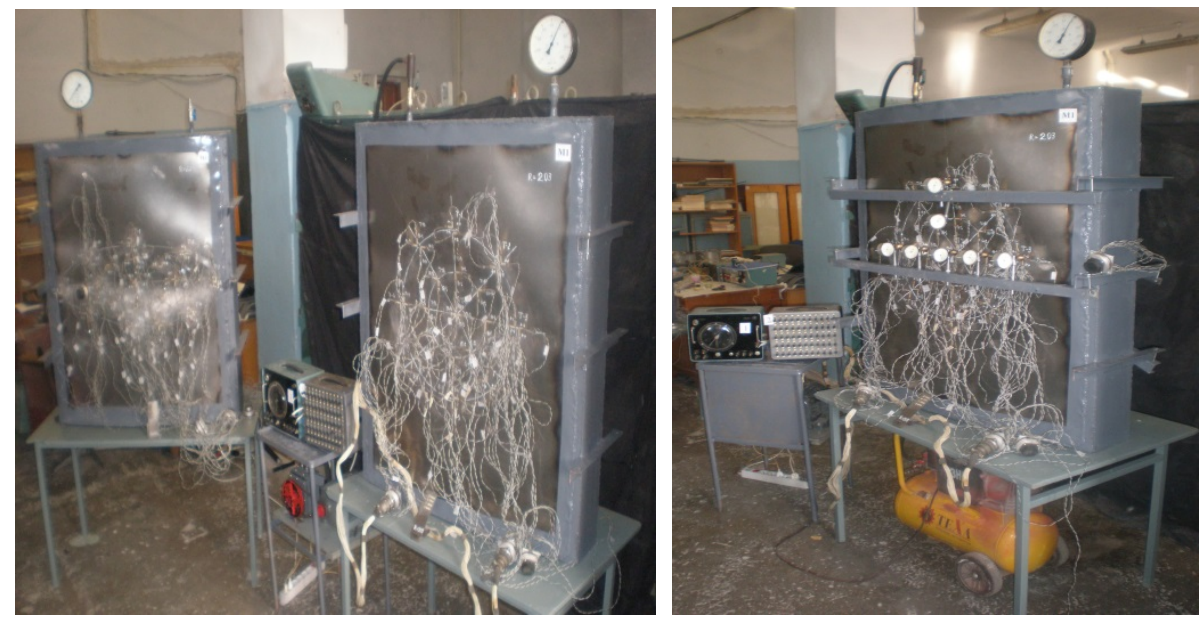

Figure 2. General view of the model fragment wall of the tank with hollows

Models enable testing of two hollows from the back and front sides of the wall. The reservoir model simulated hollows in spherical and ellipsoidal on the fragment of the wall. Basic geometric dimensions hollows are presented in Table 1.

The hollows in the model M1 is modeled by crumpling walls with special stamps and model M2 is by selection process and circuit welding at the end portions of the sheet wall.

Table 1. Shape and dimensions of hollows on the wall model

\begin{tabular}{ccccccc}
\hline Model & $\begin{array}{c}\text { Surface of } \\
\text { the model }\end{array}$ & Hollow shape & \multicolumn{2}{c}{ hollow radius, mm } & \multicolumn{2}{c}{ Depth of a hollow, mm } \\
small & & big & initial & steady state \\
\hline M 1 & A & spherical & 252 & - & 4,32 & 3,68 \\
& B & elliptical & 185 & 820 & 3,53 & 2,71 \\
M 2 & A & elliptical & 175 & 830 & 4,86 & 3,73 \\
& B & elliptical & 190 & 640 & 2,84 & 1,84 \\
\hline
\end{tabular}

The choice of instruments, equipment and primary transducers deformation was carried out taking into consideration the expected values of the experimental data.

The load from internal fluid pressure in the tank was simulated by air being blown into the shell by the compressor, and the deflected mode in the zone of the wall model hollows determined by measuring of the strain of the relative deformation. The resistive-strain sensors were placed in such a way to allow the measurement of circular and longitudinal relative deformations along the contour of hollow in the local maximum depth of bend and abrupt change in the shape of the wall.

To measure the displacing of the wall in the zone of the wall defect in the form of hollows in characteristic points of the wall is set indicators of displacing.

In identifying the phenomenon "latching" (flap) of the wall model loading model is stopped, and the readings were taken.

The factor of stress concentration defined as the ratio of the membrane stresses in the zone of the wall to the stresses in the characteristic points of the wall hollows.

The test findings were processed in compliance with the procedures and methods for solving practical problems of statistics, when measured values are random and normally distributed, in accordance with existing standards. 


\section{Results of the Study}

The results of the experiments.

In the first stage of experiments were studied the variation in depth hollows at the initial loading and unloading from the nominal stress in the wall of the model, in accordance with Figure 3

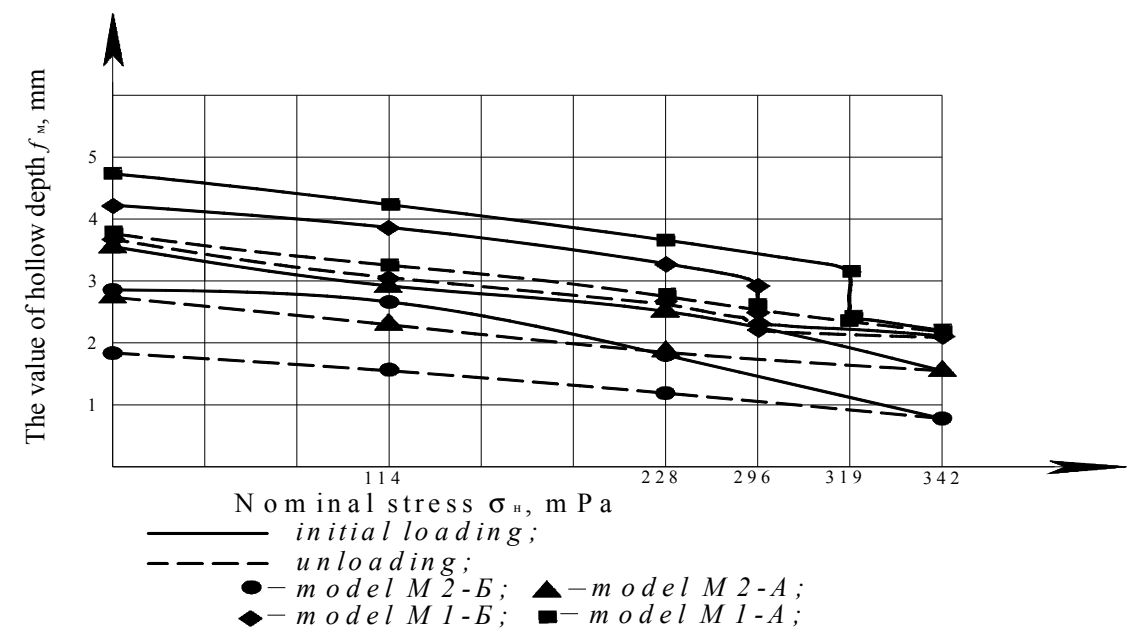

Figure 3. Changes in the value of the depth $f$ of the center of hollows depending on the nominal stress $\sigma_{H}$

When the initial loading causes an irreversible decrease in the depth of the hollows, which depends on the applied load. For comparison, Figure 3 shows the calculated according to the formula

$$
\frac{f}{f_{0}}=1-0,6 \frac{\sigma_{H}}{\sigma_{B}},
$$

dependence of the residual hollow depth $f_{0}$ from nominal stress $\sigma_{H}$ [13].

In the formula (1) $\sigma_{H}=p R / t, p-$ internal pressure, $t-$ thickness of the wall, $\sigma_{B}$ - tensile strength of the wall material.

It is established that the dependence of the residual depth in the center of the hollow $f_{0}$ from the rated stress described by equation (1) does not accurately describe the experimental data. This is due to a large deformable wall of the tank and it's thin-walled.

It is offered for tanks with high deformability wall to use the following transformed equation:

$$
\frac{f}{f_{0}}=1-0,4 \frac{\sigma_{H}}{\sigma_{B}}
$$

The calculated values of the depth of depressions in the above formula are shown in Figure 3.

During the tests on models M1 and M2-A have been reported the phenomenon of latching (flap) of the wall in the zone of the hollows, which is consistent with the work of Feodosev V.I. (14). According to this work the phenomenon of latching can be observed in relation to the depth of hollows in the wall thickness of the shell $f / t \geq 3,5$.

In model M1-A with the spherical hollow depth $f=4,32$ мм, in accordance with Figure 3, the phenomenon latching of the wall in the zone of the hollows were observed at an internal pressure of $28 \mathrm{kPa}$. The depth of the hollow was reduced to $2.06 \mathrm{~mm}$, which are more than half the initial depth and $55 \%$ of the established depth of hollows.

The model M2-A with elliptical dent depth is $4,86 \mathrm{~mm}$ this phenomenon was observed at the pressure of $26 \mathrm{kPa}$. The initial depth of hollows decreased to $2,34 \mathrm{~mm}$.

In the case of the spherical hollow (model M1-A) when unloading the wall after latching returned to its original position, and in the case of elliptical hollow (model M2-A) after latching is not returned to its original position.

In the next stage of the experimental study was used the estimate of deflected mode of the hollow in the wall zone model to study the stress distribution in this zone and the establishment of the stress concentration factor. 
According to test results the nominal circular and longitudinal stress measured at a distance from the hollows in specific control points made in the model $\mathrm{M} \mathrm{1-A}$ at the pressure of $10 \mathrm{kPa}-11.8 \mathrm{MPa}$ and $5.52 \mathrm{MPa}$, at the pressure of $30 \mathrm{kPa}-53.61 \mathrm{MPa}$ and $17.21 \mathrm{MPa}$ in the model $\mathrm{M} 1-\mathrm{B}$ at the pressure of $10 \mathrm{kPa}-11.92 \mathrm{MPa}$ and $5.83 \mathrm{MPa}$, at $30 \mathrm{kPa}-35.36 \mathrm{MPa} 17.08 \mathrm{MP}$ a model M2-A at the pressure of $10 \mathrm{kPa}-12.25 \mathrm{MPa}$, at the pressure of $30 \mathrm{kPa}-34.91 \mathrm{MPa}$ and $16.97 \mathrm{MPa}$ respectively.

It was found that in the outer border zone of the hollow has a discharge zone, where the local stress is below the rated stress. This fact was also observed in work (14). Thus, in the model M1-A is decrease by up to 1.2 times in the model M1-B - to 1.06-times, in the model M2-A - to 1.15-times. Reduced stress on the outer boundary zones of hollows, due to the influence of the bursting of the bent portion of hollows. Away from the boundaries of the hollow zone the circular and longitudinal stresses in the wall of the model are close to the nominal membrane stress, which indirectly confirms the validity of the assumptions underlying the study.

The highest stresses were observed at the center of a hollow in all models, wherein the circular stress is approximately exceeded two times than the longitudinal. With increasing pressure in the model the concentration of the circular stress in the zone of the hollows were redistributed to the lateral boundary zones of hollows, due to arching and a decrease in the depth of hollow with increasing of load.

In the models M1 and M2-B-B where there were observed a smooth transition to the contour of the wall surface of the hollows, the zone of maximum stress at the initial stage of loading are in the middle of the hollows. The effect "latching" of the wall in the zone of the hollows to achieve the highest level of pressure was not observed.

The model M2-A when the internal pressure reaches $26 \mathrm{kPa}$, an effect of "latching" of the wall in the zone of the hollows, which was accompanied by flap and sharp bending of central zone of hollows outside. Point in time of latching of the wall zone hollows accompanied by a transition zone of maximum stress and strain to the lateral contour points, with a sharp increase in stress in the boundary areas of the hollows. In the middle of the defect the flap accompanied by instantaneous strain, due to a decrease in the depth of hollow as a result of its bending.

Diagrams of circular stress built by the experimental data and presented in Figure 4 indicate the specific stress concentration in the area of greatest depth of hollows and the influence of the geometric dimensions and character lines of crossing the border hollows to the wall model.

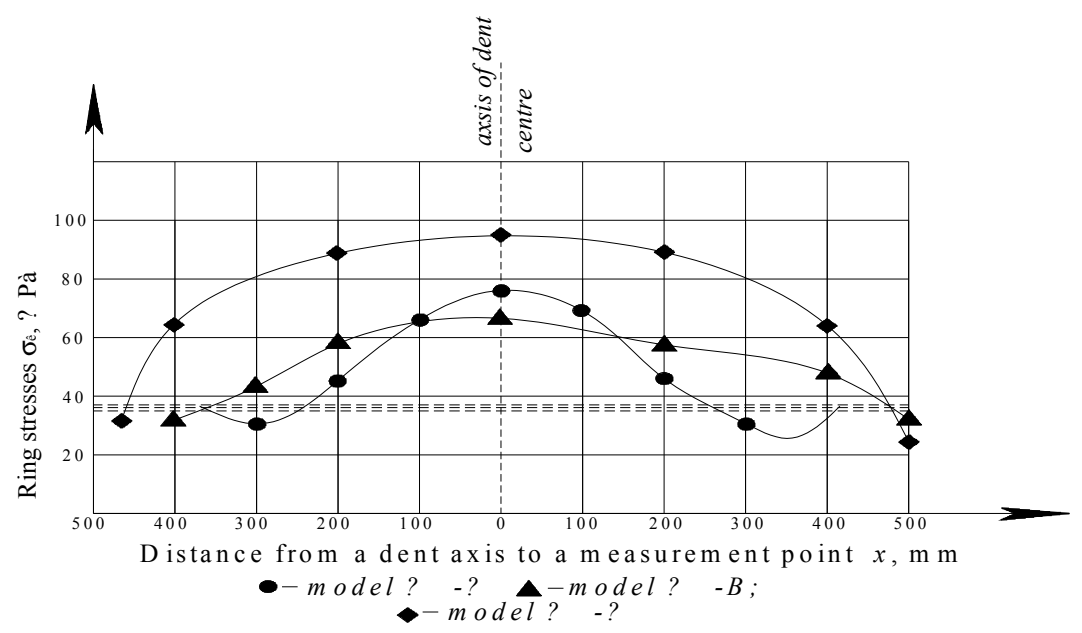

Figure 4. Diagrams of the circular stress in the zone of the hollows

The results of determination of the stress concentration factor are shown in Figure 5. 


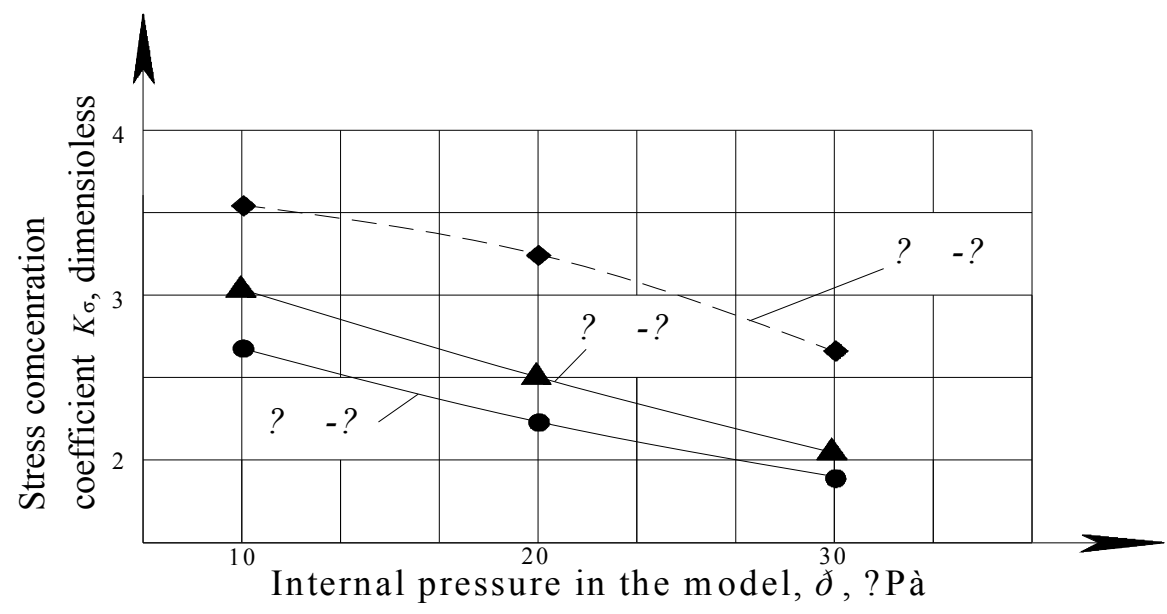

Figure 5. The dependence of the concentration of stresses in the hollows of the internal pressure in the model

It is found that with increasing pressure in the model coefficients of stress concentration in the central zone of the hollows has decreased in numbers: in the model M1-A by 30\%, the model M1-B-by 31\%, the model M2-A by $26 \%$, due to straightening dents at increasing of internal pressure in model.

It is observed that with increasing pressure in the central zone of the model intensity of hollows decreases and the sphere of maximum stress shifts to the borders of the hollows. At the moment of latching of the wall model in the zone of the hollows observed sharp decrease stress concentration factor in strengthening in the close zone to the borders of the hollows.

\section{The Theoretical Results}

At this stage of the work were carried out the theoretical studies of the deflected mode of the tank wall, taking into account the concentration of stresses in the hollows.

Using the hypothesis presented in the studies $(15,16)$, that the stress concentration factor of the defect shape of the cell is determined by two parameters $f / t$ и $r / \sqrt{R t}$, т.e.

$$
K_{\sigma}=\Phi(f / t ; \quad r / \sqrt{R t})
$$

The check of an admissibility of expression is made (3) for vertical cylindrical tanks with dented walls of different sizes and its evaluation in terms of the results obtained in the experimental part of the work.

The main empirical formula to determine the stress concentration factor obtained by aligning the individual obtained by experimental tests of the reservoir model design, data with the surfaces of the given form.

Using the dependence of the stress concentration factor in the zone of hollow on the ration of the depth of hollows $f$ to the thickness of the wall $t$ at corresponding values of parameter $r / \sqrt{R t}$, the tanks defined by modeling tests, factor of concentration of stress in an interval $, f / t=2 \ldots 18, r / \sqrt{R t}=1 \ldots 10$ it is offered to approximate power dependence of a kind:

$$
K_{\sigma}=X\left(\frac{f}{t}\right)^{Y} .
$$

Selection of numerical values of the coefficient $X$ and $Y$ produced by the method of least squares. We obtained the following values:

$$
X=3,0825+0,4393\left(\frac{r}{\sqrt{R t}}\right)-0,0960\left(\frac{r}{\sqrt{R t}}\right)^{2}+0,0083\left(\frac{r}{\sqrt{R t}}\right)^{3}-0,0002\left(\frac{r}{\sqrt{R t}}\right)^{4}
$$




$$
Y=0,3433+0,0966 \ln \left(\frac{r}{\sqrt{R t}}\right) .
$$

In the formula (1), (6) $f$-depth of the hollow; $r$-radius of the hollow; $t$-thickness of the wall; $R$-radius of the tank.

The division into design interval parameters $f / t$ и $r_{b} / \sqrt{R t}$ reduces the average fractional error of the formula (4) with significant geometric dimensions of hollows, as well as greatly simplify the design equation and is limited by polynomial of the second degree.

Testing models fragment of the tank wall with the hollow of significant dimensions and small thicknesses was found the effect "latching" of the wall in the zone of hollows, which resulted in sharply reduced hollow depth, and the maximum stress in the central zone are distributed in the contour zone. At that significantly lowers the stress concentration in the central zone of hollows and an increase in its contour areas is observed.

Analysis of the results of deflected mode of the wall in the zone of the hollows fully confirms the assumption that the local defect in the form of dents in the wall of the reservoir model, loaded with internal pressure, leads to a local dithering of the stresses in the zone of the hollow.

\section{Discussion of Results}

It should also be noted that in models with distinctive arching borders of the hollow the stress concentration factors in the zone of the coast hollows are much more than in the models, where the borders of dents smoothly transfer into the main wall of the model. This fact is due to the fact that the edges of bend by the borders of hollows give a certain rigidity of the area and lead to increased stress. When smooth arching borders of hollows in the process of loading the internal pressure, the area is deformed together with the zone on the outer wall of the boundaries of dents, resulting in a smoothed type of stress diagram in this area.

The findings in the theoretical part of the formula (4), (5) and (6) give possible to analyze the maximum stress concentration factors in the zone of the hollows, depending on the geometry of the hollows and reservoirs.

\section{Conclusion}

Complex tests of models fragment of tank wall with hollows established features of the distribution of stresses, their concentration in the zone of the hollows, as well as the dependence of the stress on the dimensions and shape of the hollows. In dents significant geometrical sizes is set the effect "latching" of the wall model, in consequence of redistribution of stresses in the zone of the hollows.

The findings of the study allow more complete and reliable estimate of the deflected mode of the wall cell in the zone of hollows, to prove the need to incorporate in the analysis of the stress concentration in the zone of hollows, to develop a methodology of strength analysis and durability of tanks for hollows, as well as create the preconditions for the normalization of the limit of geometrical dimensions of hollows and significantly complement the previously known data on the deflected mode of the wall cell in the zone of the hollow and make it possible to improve design standards.

The perspective direction for further research in this problem is to develop science-based engineering design procedure of the tanks with hollows in the wall, as well as studies of the effect of stress concentration in the zone of hollows on low-cycle fatigue and durability of the reservoir structures. The research related to the development of methods of valuation limit of geometrical dimensions of the hollows is appealed too.

\section{Acknowledgements}

The performance of work is conducted under the contract to perform the research work under the state order on the program "Grant funding for scientific research" with the Committee of Science, Ministry of Education and Science of the Republic of Kazakhstan.

The authors wish to thank members of the laboratory of mechanical tests of M. Auezov South Kazakhstan State University for assistance in carrying out of modeling tests.

\section{References}

Ainabekov, A. I. et al. (2009). The engineering technique of an estimation of the intense-deformed condition of a zone of defect of the wall of the vertical cylindrical tank in the form of hollows. Mechanics and Modelling of Processes of Technology, 1, 49-53.

Alifanov, L. A. (2001). The estimation of the distributions connected with local defects of the form of steel tanks. Theses of reports scientifically-methodical conference. Norilsk, 256-258. 
American Petroleum Institute (2001). API Standard 650 Welded Steel tanks for oil storage. Tens edition, Addendum 2, Washington.

BN PK (2004). The instruction on designing, manufacturing and installation of vertical cylindrical steel tanks for oil and oil products. Intr. Astana, p. 78.

BS-5500. (1976). Specification for Unfired fusion welded pressure vessels. British Standards Institution.

Doroshenko, F. E. (2007). Residual voltage and ways of increase of reliability and durability of vertical cylindrical storage reservoir. Assembly and Special Works in Building, 5, 11-12.

Feodosev, V. I. (1946). For the calculation of flap membrane. Applied Mathematics and Mechanics, 10(2), $162-175$.

Fillipov, V. V. et al. (1993). Buslaev I.I. Technical condition of tanks for storage of oil products association "Jakutsknefteprodukt". News of high schools. Building, 7(8), 13-16.

Ivanov, G. P., \& Razbitnoy, S. A. (2000). The method of an estimation of pressure from hollows on the wall of the cells, working under pressure. Chemical and Oil Mechanical Engineering, 4, 18-19.

Kupereshvili, C. M. (2005). Mechanics of destruction of vertical cylindrical tanks. Industrial and Civil Building, $5,40-42$.

Kuznetsov, V. V., \& Kandakov, G. P. (2005). The Problems of domestic storage reservoir building. Industrial and Civil Building, 5, 17-19.

Lihman, V. V. et al. (1995). The durability of welded tanks with malconformation at low-cycle stress. The Problems of Durability, 1-12, 130-136.

Likhman, V. V. et al. (1992). Concentration of pressure in tanks with local malconformation. Chemical and oil mechanical engineering, 6, 22-24.

Mukhin, V. N., \& Elmanovich, V. I. (1991). The settlement and experimental estimation of influence of local hollows on durability of cases of cells and devices. Chemical and Oil Mechanical Engineering, 6, 24-26.

SR 03-605-03. (2002). Rules of the device of vertical cylindrical steel tanks for oil and oil products. Gosgortekhnadzor of Russia, 83.

VBN V.2.2-58.2-94 (1994). The vertical steel storage reservoir for storage of oil and oil products with pressure of sated steams not above 93,3 кPa. Kiev: Goskomneftebaz, 98.

\section{Copyrights}

Copyright for this article is retained by the author(s), with first publication rights granted to the journal.

This is an open-access article distributed under the terms and conditions of the Creative Commons Attribution license (http://creativecommons.org/licenses/by/3.0/). 